Article

\title{
Requirement of Simultaneous Assessment of Crystal- and Supernatant-Related Entomotoxic Activities of Bacillus thuringiensis Strains for Biocontrol-Product Development
}

\author{
Ronaldo Costa Argôlo-Filho ${ }^{1, *}$, Robson Luz Costa ${ }^{2}$, Daniele Heloisa Pinheiro ${ }^{3}$, \\ Fábio Mathias Corrêa ${ }^{4}$, Fernando Hercos Valicente ${ }^{3}$, Alan William Vilela Pomella ${ }^{2}$ and \\ Leandro Lopes Loguercio ${ }^{1}$
}

1 Department of Biological Sciences (DCB), State University of Santa Cruz (UESC), Rod. BR 415, Km-16, Ilhéus-BA 45662-900, Brazil; E-Mail: leandro@uesc.br

2 Farroupilha Laboratory, Av. Cica No. 555, Patos de Minas-MG 38706-420, Brazil; E-Mails: robsonluzcosta@yahoo.com.br (R.L.C.); alan@grupofarroupilha.com (A.W.V.P.)

3 Embrapa Maize and Sorghum, Rod. MG 424, Km 65, Sete Lagoas-MG 35701-970, Brazil; E-Mails: daniele.hp@hotmail.com (D.H.P.); fernando.valicente@embrapa.br (F.H.V.)

4 Department Exact and Technological Sciences (DCET), State University of Santa Cruz (UESC), Rod. BR 415, Km-16, Ilhéus-BA 45662-900, Brazil; E-Mail: fmcron@gmail.com

* Author to whom correspondence should be addressed; E-Mail: ronaldoargolo@yahoo.com.br; Tel.: +55-73-3680-5183; Fax: +55-73-3680-5226.

Received: 6 February 2014; in revised form: 29 April 2014 / Accepted: 12 May 2014 / Published: 20 May 2014

\begin{abstract}
Bioinsecticides with lower concentrations of endospores/crystals and without loss of efficiency are economically advantageous for pest biocontrol. In addition to Cry proteins, other Bacillus thuringiensis (Bt) toxins in culture supernatants (SN) have biocontrol potential (e.g., Vip3A, Cry1I, Sip1), whereas others are unwanted ( $\beta$-exotoxins), as they display widespread toxicity across taxa. A strain simultaneously providing distinct toxin activities in crystals and SN would be desirable for bioinsecticides development; however, strains secreting $\beta$-exotoxins should be discarded, independently of other useful entomotoxins. Entomotoxicity of crystals and $\mathrm{SN}$ from a Brazilian Bt tolworthi strain (Btt01) was tested against Spodoptera frugiperda to assess the potential for biocontrol-product development based on more than one type of toxin/activity. Tests showed that $10^{7}$ endospores $\mathrm{mL}^{-1}$ caused $>80 \%$ of larvae mortality, suggesting Btt01 may be used in similar concentrations as those of other $B t$-based biopesticides. When it
\end{abstract}


was applied to cornfields, a significant $60 \%$ reduction of larvae infestation was observed. However, bioassays with Btt01 SN revealed a thermostable toxic activity. Physicochemical characterization strongly suggests the presence of unwanted $\beta$-exotoxins, with isolate-specific temporal variation in its secretion. Knowledge of the temporal pattern of secretion/activity in culture for all forms of toxins produced by a single strain is required to both detect useful activities and avoid the potential lack of identification of undesirable toxins. These findings are discussed in the contexts of commercial Bt product development, advantages of multiple-activity strains, and care and handling recommended for large-scale fermentation systems.

Keywords: protein secretion; feeding bioassays; beta-exotoxin; Cry; alternative $B t$ toxins; culture supernatant

\section{Introduction}

Bacillus thuringiensis (Berliner) (Bt) is an entomopathogenic bacterium found in many different environments, producing a variety of Cry proteins during sporulation that are selectively toxic to various insect pests [1-3]. Once ingested by the target insect, these proteins cause osmotic imbalance and intestinal paralysis which lead to inanition, sepsis and death [4]. These characteristics have been successfully explored in the past 60 years in the field of biological control of insect pests. However, due to the emergence of resistant pest populations along with the use of $B t$-based insecticides, obtaining new $B t$ strains and/or toxins that are more effective and selective in the control of these insect races is a constant focus of research [5]. In addition to the most widely used Cry proteins, several other insecticide molecules are produced by Bt, such as Cyt (cytolytic), Vip (vegetative insecticidal protein), Sip (secreted insecticidal protein), phospholipase $C$ and exochitinase [6-9]; these have also been studied for potential use in biocontrol. However, not all of these alternative $B t$ toxins can be used for pest control, as it is the case with $\beta$-exotoxin (Thuringiensin). This is a thermostable compound of low molecular weight (701 Da) that is analogous to adenine or uracil nucleotides [10,11], showing its toxic action by interfering with processes of DNA-dependent RNA polymerization [12]. Therefore, it has a wide spectrum of biological toxicity over a variety of non-target species, including mammals. Such a characteristic has led the World Health Organization to prohibit the use of $\beta$-exotoxin-producing $B t$ strains in bioinsecticide formulations. Genes that regulate the synthesis of $\beta$-exotoxins in $B t$ are located in plasmids that also encode some Cry proteins [10].

Brazil is the third largest producer of maize (Zea mays L.); its cultivated area is 14.33 million hectares and 2011/2012 production was approximately 58 million tons, making up 8\% of world production [13]. The fall armyworm, Spodoptera frugiperda (J.E. Smith) (Lepidoptera: Noctuidae), is a major pest of maize in several countries, causing production losses of approximately $30 \%-50 \%$ [14]. For its relevance to the world's corn market, devising economically and environmentally acceptable control methods for this pest is yet a research focus, for which integrated pest management (IPM) has offered the best approaches [15]. For many years, the major form of armyworm control has been the use of synthetic chemical insecticides, which are well known to have caused deleterious effects to 
ecosystems and toxicity to humans [16-18]. Several forms of biological control using natural predators, live microorganisms or their metabolites, plant extracts, and viruses have been developed in order to minimize this impact [1,19-22]. In this context, the use of Bt-based biopesticides is highlighted, because toxins of certain strains have successfully controlled fall armyworm, by either direct application or plant transformation [23-25]. Furthermore, only recently the tropical germplasm of $B t$ has started to be investigated for their potential in biocontrol of fall armyworm races, in the context of corn production in Brazil [26-28].

To assure economy and competitiveness for biopesticide production, the use of bacterial strains producing large quantities of toxins that are efficient at lower concentrations is desirable. In Brazil, $B t$ germplasm from tropical and temperate regions (e.g., HD series) have been described as being highly effective against fall armyworm. A tropical Bt strain, "Btt01," has been characterized and identified as belonging to the subspecies tolworthi; it produces a bipyramidal crystal of $\delta$-endotoxins and its $\mathrm{LC}_{50}$ was estimated to be $\sim 8 \times 10^{6}$ endospores $\mathrm{mL}^{-1}$ for fall armyworm [25]. This suggest the possibility of its use in similar concentrations to those of commercial products, especially the HD1-based biopesticides $\left(\mathrm{LC}_{50}\right.$ of $6 \times 10^{6}$ endospores $\left.\mathrm{mL}^{-1}\right)$ used to control this pest [29,30]. In addition, entomotoxic activities of proteinaceous nature that are secreted in its culture supernatant (SN) at the $\log$ phase have also been evaluated [28,31,32]. Taking this information into account, and aiming at improving the economic potential of exploring this strain for the biocontrol market, we evaluated entomotoxic activities against fall armyworm from pellet (crystals) and from SN. Such a possibility of having two distinct toxic activities from the same culture time in a large-scale fermentation system would certainly be technically and economically advantageous. Thus, using Btt01 as the experimental model, this study aimed to verify: (i) whether the use of the lowest possible initial endospore concentration of this strain is agronomically viable for fall armyworm biocontrol in the field; (ii) whether there is suitable entomotoxic activity for use in biocontrol-product development in culture $\mathrm{SN}$ collected at the same time that the endospores and crystals are obtained under industrial-scale fermentation; and (iii) whether temporal assessments of toxins synthesis/secretion during a $B t$ culture is relevant for decision-making processes regarding bioinsecticide production. Because an unequivocal detection of the undesired $\beta$-exotoxin was found in the $B t t 01$ strain, the results taken together indicate that concomitant evaluations of both fractions containing toxins in $B t$ cultures (pellet and $\mathrm{SN}$ ), coupled with assessment of their temporal synthesis/secretion during culture are fairly necessary for more efficient and environmentally safer large-scale production schemes involving promising isolates.

\section{Results}

\subsection{Entomotoxicity of Btt01 $\delta$-Endotoxins in Laboratory and Field Bioassays}

Preliminary studies have shown that the Btt01 strain displays a higher $\delta$-endotoxins activity against $S$. frugiperda than other $B t$ isolates [25]. In this study, we tested a standardized concentration of $10^{7}$ endospores $\mathrm{mL}^{-1}$ for this strain, which is similar to other commercial $B t$-based products and preserves satisfactory biocontrol effects. Firstly, three different diet types (artificial, detached leaves and V4-stage maize plants) were assessed to verify whether they would affect the results of larvae mortality by the Cry toxins from the Btt01. The results showed that the tested concentration was 
efficient for larvae control, with an overall mortality rate of $\sim 80 \%$. Although there was no significant difference between diet types, the artificial one became the best option because of lesser experimental variation. The high overall mortality in all diet treatments indicated that they did not inactivate the toxins or prevent the larvae access to them (data not shown).

After the feeding bioassays at laboratory scale have confirmed the entomocidal efficiency of this strain, field trials were carried out with the dual purpose of verifying whether this high toxicity was maintained under field conditions, and to assess the effects of irrigation on the efficiency of the toxins applied. Tests were performed under usual conditions of irrigation (center pivot system applying $3 \mathrm{~mm}$ water $\mathrm{day}^{-1}$ ) and insecticide applications on maize crops (Figure 1). Results from the non-irrigated maize showed that the application of $B t t 01$ at $10^{7}$ endospores $\mathrm{mL}^{-1}$ was effective in controlling S. frugiperda infestation in the field. Larvae infestation decreased to less than half of negative control, and did not significantly differ from the synthetic insecticide effects (Figure 1A). On the other hand, effects of the $B t t 01$ on the irrigated crop did not significantly reduce larvae infestation (Figure 1B). Comparing both cases by the Abbott's formula [33], the efficiency of Btt01 Cry toxins in non-irrigated crop was $60 \%$, but only $17 \%$ in irrigated maize, indicating a reduction of $71.7 \%$ in the biocontrol efficiency. Similarly though, the synthetic insecticide also showed a reduction in armyworm's control efficiency, decreasing from $100 \%$ in non-irrigated maize to only $53 \%$ in the irrigated crop.

Figure 1. Btt01 Cry toxins insecticidal activity against $S$. frugiperda in (A) non-irrigated and (B) center-pivot irrigated maize fields. The synthetic insecticide Lannate $\mathrm{BR}^{\circledR}$ (DuPont) was used as positive control. The infestation level was verified by the number of plants with characteristic signs of injury. The results show the means of 3 replications + std error. Statistical differences were determined by contingency $2 \times 2$ chi-square tests on the data from directly counting the number of larvae infestations $(* p<0.05)$.
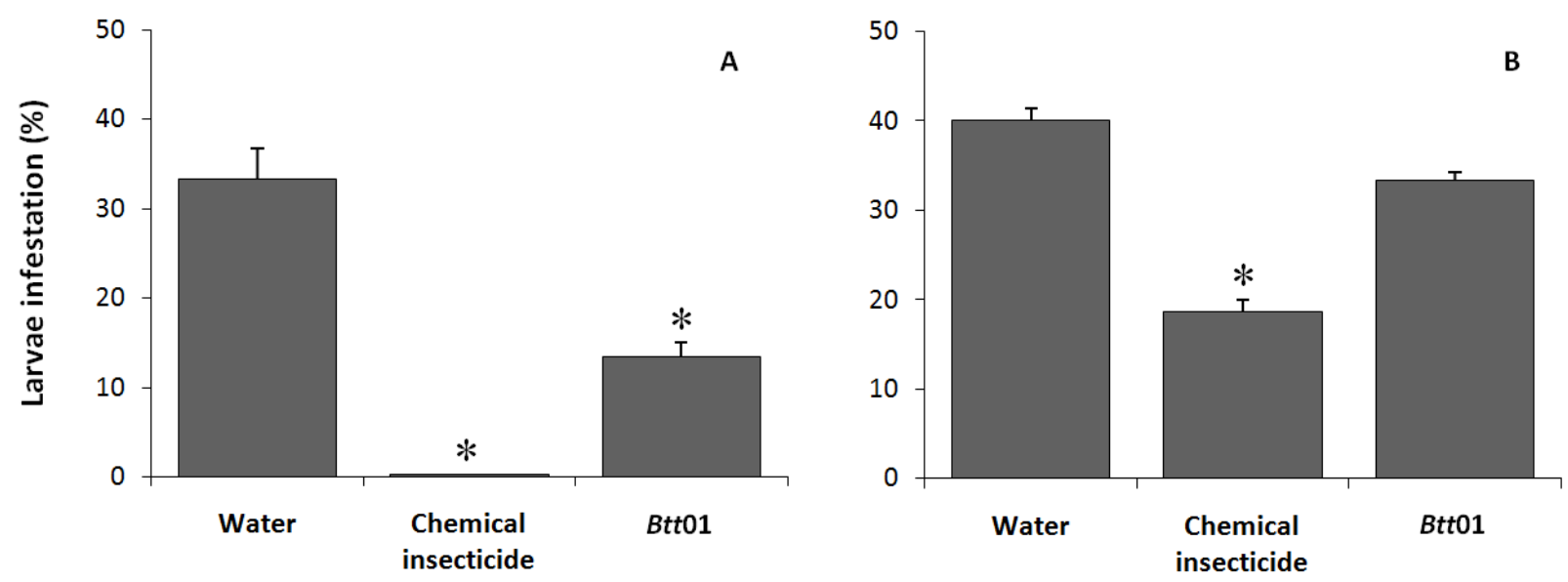

\subsection{Entomotoxicity of Btt01 Supernatant}

Based on previous studies at laboratory scale [28,31,32], this strain has also shown some promise as a source of useful entomotoxic activity secreted in the SN. The possibility of using the SN of Btt01 as an alternative source of useful entomotoxins was thus verified by applying the residual liquid fraction of a large-scale fermentation, from the same time used to produce spores, in feeding bioassays. The results 
showed that toxicity of this SN against $S$. frugiperda was very high, even when a remarkable dilution to only $5 \%$ of the initial concentration was performed. Although it could have indicated desired results, the fact that such an activity was fully thermostable demonstrated otherwise; the heated SN at a high temperature showed identical levels of mortality ( $98 \%$ ) in relation to the non-heated treatment (Figure 2). Therefore, the whole activity observed for this SN was due to a non-proteinaceous form of toxin.

Figure 2. Btt01 supernatant toxic activity against $S$. frugiperda. Artificial diets were soaked in unheated (SN) and heated $(\mathrm{SN}-\Delta)$ supernatant. The $\mathrm{SN}-\Delta$ treatment corresponds to heating in water bath at $\sim 100{ }^{\circ} \mathrm{C}$ for $20 \mathrm{~min}$. The percentage values at the $\mathrm{x}$-axis refer to $\mathrm{SN}$ concentration in sterile water. The results are the mean of 3 replicates + std error. Statistical differences were determined by contingency $2 \times 2$ chi-square tests on data from directly counting the number of dead larvae $(* p<0.05)$.

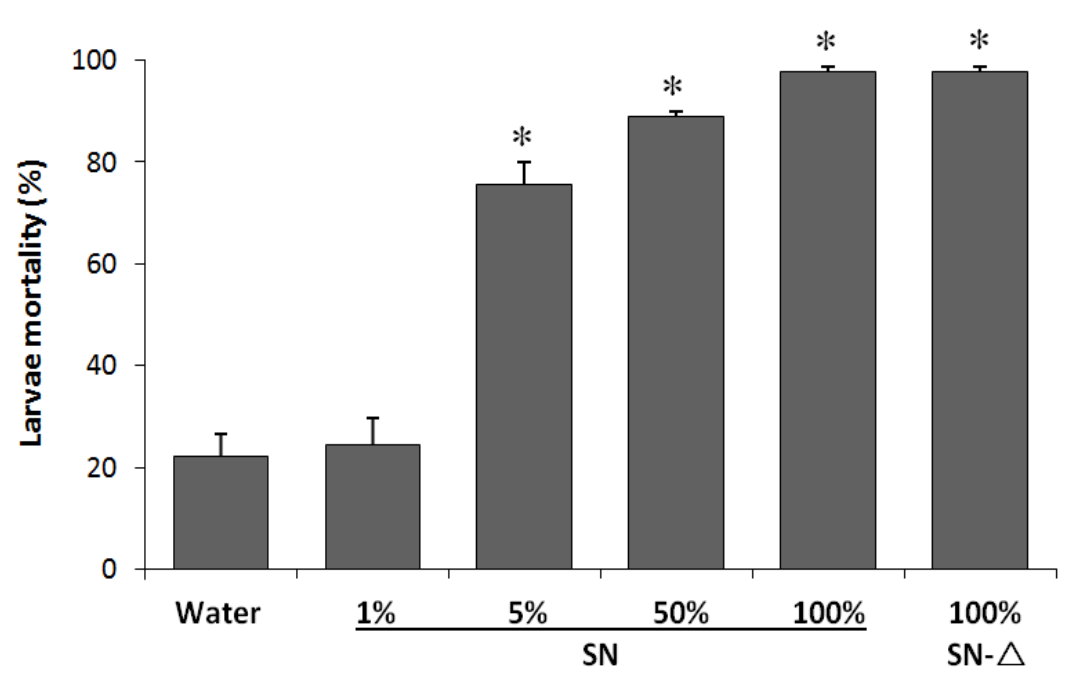

Some $B t$ strains are producers of the non-protein, thermostable $\beta$-exotoxins [10], which show a large spectrum of toxicity across taxa. Two other Btt strains, HD125 and T09, derived from temperate climates (USA and France, respectively), are known to produce $\beta$-exotoxins [34,35]. In order to confirm whether the Btt01 strain from a tropical origin (Foz do Iguaçu-PR, Brazil) also produces this same type of toxin, an experiment was carried out to compare the toxic activities of these strains. Treatments known to eliminate the $\beta$-exotoxin toxic activity (see Experimental Section) were tested simultaneously with others that do not (Figure 3). Bioassays using Btt01 SN against $S$. frugiperda showed high mortality levels of the same magnitude of those displayed by HD125 and T09 strains, when treated only with high temperature. However, SN treatments based upon alkaline phosphatase digestion, or heating at low $\mathrm{pH}(<3.0)$ tend to inactivate this toxin $[9,33]$. The mortality results for all three strains with their SNs treated in these two ways confirmed a tendency of inactivation of the thermostable toxic activity. However, at least under the conditions employed in this study, a complete inactivation was not observed. Furthermore, a strain-specific inactivation effect for the alkaline phosphatase treatment was also observed (Figure 3). Taken together, these results indicated that the $B t t 01$ tropical strain produces at least one type of $\beta$-exotoxin in its $\mathrm{SN}$, under the same large-scale culture conditions used to produce the endospores suitable for biocontrol purposes. 
Figure 3. Feeding bioassay against $S$. frugiperda with different inactivation treatments for the thermostable toxin in the SN of three Bt strains. Artificial diets were soaked in SN treated as indicated in the legend on the right. The results are the mean of 4 replicates + std error. Statistical differences were determined by contingency $2 \times 2$ chi-square tests on data from directly counting the number of dead larvae $(* p<0.05)$.

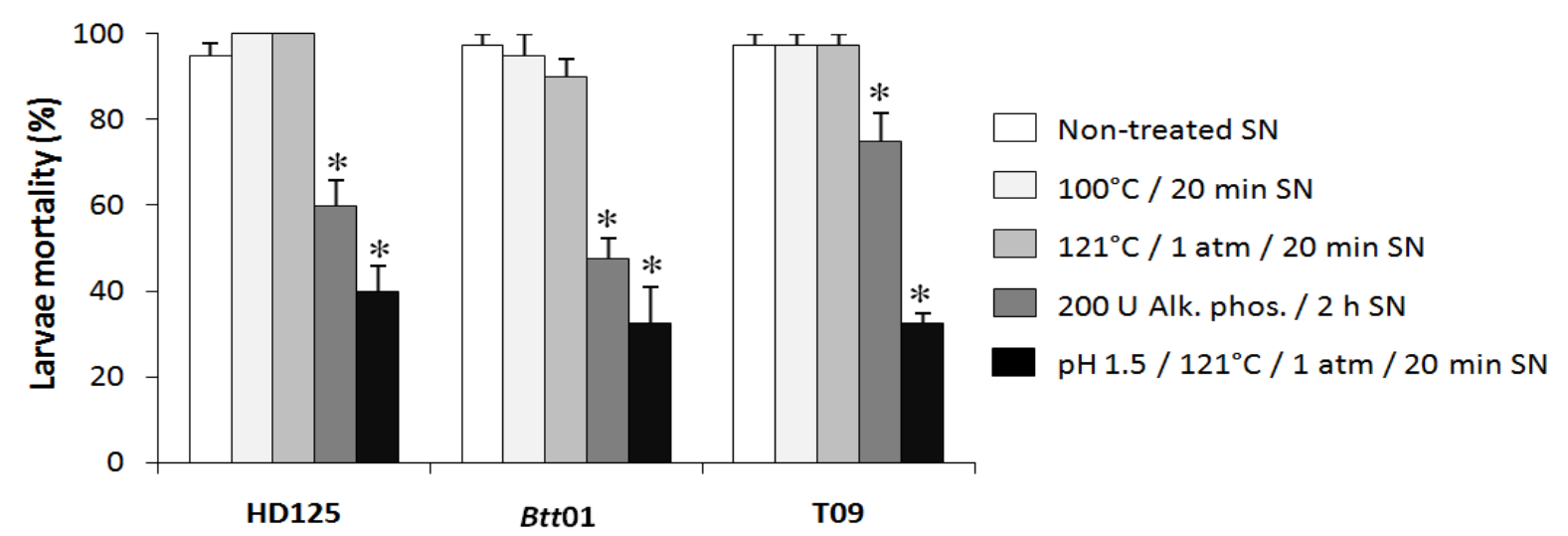

Differences in proteotoxin secretion among isolates during bacterial growth have shown to interfere with the final toxic effects of the respective SNs [28]. It was thus necessary to determine whether a similar temporal regulation also occurred with secretion of low-weight metabolites, such as the $\beta$-exotoxins. The existence and extent of this possible temporal variation, and how it would affect the insecticidal activity of the strains, were evaluated under small-scale (laboratory) culturing conditions. Despite being inoculated and cultured in the same way (see Experimental Section), the studied strains varied in relation to the time that production/detection of thermostable toxin first occurred, as well as to the highest mortality levels achieved by each one (Figure 4). HD125 and Btt01 began to show toxicity with $\sim 72-80 \mathrm{~h}$ of incubation, rapidly reaching a peak at $\sim 96-100 \mathrm{~h}$, and remaining at similar levels afterwards. However, the mortality levels achieved by the HD125 were always greater than $B t t 01$, with a tendency for another increase later on $(144 \mathrm{~h})$, whereas the latter showed a declining pattern (Figure 4A). In contrast, the T09 strain began to show toxicity only later, after $\sim 90-96 \mathrm{~h}$, and reached its maximum level at $\sim 120 \mathrm{~h}$, remaining so until the end. At the last two time points, mortality of this strain was very similar to the Btt01. After the 96-h time point, the HD125 showed higher levels of larvae mortality than others. In the experimental conditions used, the sporulation phase for the three strains started at $\sim 72 \mathrm{~h}$. Generalized modeling with a logistic regression showed statistical significance $(p<0.01)$ for the individual effects of the factors "isolates" and "culture time" and for their interaction $(p<0.05)$ (Figure 4B). For any given mortality proportion $>0.18$, the isolates differ in their timing in which thermostable toxicity is secreted to provide such mortality; for instance, a dead larvae proportion of 0.2 is achieved at $\sim 65,71$ and $93 \mathrm{~h}$ of culture for HD125, Btt01 and T09, respectively. 
Figure 4. Temporal profile in culture of thermostable toxic activity against $S$. frugiperda from SN of three $B t$ strains. Cultures were performed at small-scale laboratory conditions. (A) Temporal profile of the number of dead larvae per isolate (given in \%), per culture time. Dashed line corresponds to the average levels of mortality in the bioassay controls with only water application to the diets. The results indicate the means of 8 replicates + std error; (B) Generalized models of larvae mortality per isolate as a function of culture time, with a logistic regression. Statistical deviance analyses were performed for the variables "isolates" and "culture times" individually, as well as of their interaction; all results showed significance at $p<0.05$ (see Experimental Section).
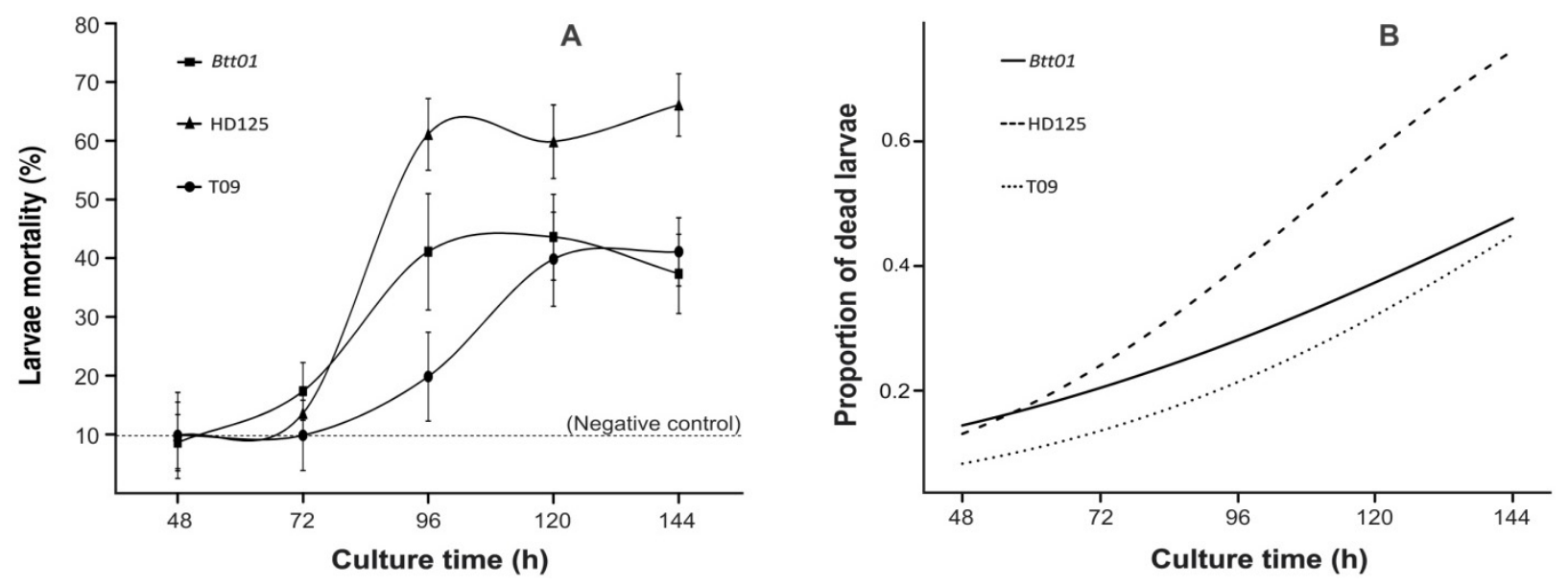

\section{Discussion}

The three most relevant challenges that integrated insect-pest management (IPM) programs must overcome are (i) assurance of economic viability, efficiency, and environmental sustainability of the control measures; (ii) reduction or elimination of threats to environment and health; and (iii) prevention or delay of resistance development by the target pest [15,36,37]. The aspects to be considered for proper decision-making processes in this context include the use of single or multiple suitable isolates combined with distinct mechanisms of action, better formulations and improved delivery methods [38]. Furthermore, host-specificity is a key factor to determine whether biocontrol strategies will be efficient and environmentally safer $[39,40]$. Hence, alternatives of biocontrol agents and/or derived active substances are constantly needed, leading to the search for novel isolates carrying more effective toxins and/or new specificities. The work here reported is an example of a comprehensive sequence of steps required for a full characterization of a promising biocontrol $B$. thuringiensis $(B t)$ isolate, such that both its advantageous aspects and drawbacks are discussed in the context of a most appropriate management of the production system.

In the context of $B t$ applications, a technically and economically desirable condition is to have formulations with lower amounts of endospores that keep the same efficiency of the final product. The $B t t 01 \delta$-endotoxins used in this study were highly toxic and effective against fall armyworm (S. frugiperda) at a concentration of endospores very similar to other Bt-based biocontrol products available in the market. A possible explanation for this strain efficiency would be its specific constitution of cry genes. Btt01 carries the $c r y l A b, c r y l B, c r y l E$ and $c r y l F b$ genes and their proteins 
form a bipyramidal crystal [25]. The Cryl group has been described as effective against the genus Spodoptera, whereas Cry1B and Cry1F are among the most potent proteotoxins already found [41-43]. Moreover, previous studies had shown clear advantages for this specific composition of Cry proteins (including Cry1E) on the toxicity to $S$. frugiperda under tropical conditions [26]. Therefore, on the basis of preliminary studies [26,44] and on the laboratory and field bioassays of this work, the Btt01 strain showed a great potential for use in biocontrol applications, mostly in the form of biopesticides based on parasporal inclusions of proteinaceous (hence thermolabile) nature.

Most of the screening studies reported in the literature tend to focus on laboratory assays, which do not allow observation of environmental factors affecting the $B t$ physiology or toxins. An evidence for a washing out interference of crop-applied water on the insecticidal action was observed in the field experiments (Figure 1): Btt endospores were more efficient in non-irrigated maize, even with the irrigation occurring at least $24 \mathrm{~h}$ after endospore application. Moreover, irrigation also decreased the synthetic chemical insecticide efficiency, although to a lesser extent, possibly due to a faster entomocidal action by contact. Since the synthetic insecticides are usually recommended to be used only after appearance of the first signs of insect damage, producers generally have the habit of considering the use of biocontrol products in the same way [45]. However, as general guidelines for a better efficiency of these products (confirmed in this study), bioinsecticide applications must reach the initial stages of insect development that are more susceptible [46], occurring before plant damages are visible. In any case, the control efficiency of Btt01, under our experimental conditions, was not too different from that of the synthetic insecticide, which suggests that simple management schemes that coordinate $B t$ applications (at proper pest stages) and irrigation may be sufficient to compensate for the difference between the two methods.

Because several other toxins have shown to be secreted in the $B t$ culture SNs (Vip, Cry1I, Sip, exochitinase, $\alpha$ - and $\beta$-exotoxins [9-11,47]), and because several cases of development of insect resistance to Cry toxins have already been described $[4,48]$, the search for new biological pest control alternatives has been frequent. In this context, confirming toxic effects of a SN obtained from the same large-scale fermentation stage and conditions that are used for commercial production of Crys would be two-fold advantageous: it could provide useful alternative toxins, as well as improve the economics of the production system by exploring more than one type of toxin simultaneously. However, an analysis of SN toxicity of Btt01 was important in a different sense, i.e., for a better understanding of potential limitations in Btt's physiology. In previous studies, the protein fraction of Btt01 SN have been isolated, concentrated and tested against fall armyworm [31,32]; since no relevant activity had been found, the toxic SN activity here observed (Figure 2) is likely not related to any proteotoxin. It is strongly suggested that the presence of a thermostable and highly toxic activity against $S$. frugiperda (Figure 2) was due to the undesired $\beta$-exotoxin, because it could be inactivated by phosphate ester cleavage or by high temperature treatment (autoclaving) at a very acidic $\mathrm{pH}[11,33]$ (Figure 3 ).

Thinking on alternative methods to detect $\beta$-exotoxins, a correlation between their production and the presence of crylB gene has been suggested [49], which could interestingly allow indirect detection of those toxins through easy-to-handle molecular techniques, such as PCR. However, despite this gene being found in Btt01 [25,48], parallel studies in other Bt isolates (tropical germplasm) showed that $\sim 50 \%$ of them carried the same gene, but did not present thermostable toxic activities at any point in their growth, even after the sporulation phase (not shown). This therefore suggests that PCR-based 
detection of specific $\operatorname{cry} 1 B$ aiming at identifying $\beta$-exotoxin-producing strains is not a useful technique. In terms of the thermostable toxic SN activities, it is noteworthy that the maximum levels of mortality shown in Figure 4 for Btt 01 and the other strains were different than those from experiments with industrial-scale SN (Figure 2). Possible reasons for this discrepancy could be differences in the SN collection times, culture volumes (1500 L vs. $50 \mathrm{~mL})$, inoculum conditions, and general culture conditions (industrial fermenter with aeration and $\mathrm{pH}$ control vs. culture bottles with orbital shaking and without $\mathrm{pH}$ control). In this context, it is worth mentioning that, for the Btt01 strain, endospores are produced after $24 \mathrm{~h}$ in large-scale fermentation (see Experimental section), but only after $\sim 72 \mathrm{~h}$ in small-scale culture conditions (Figure 4). In addition, the significantly higher entomotoxic activities observed for strain HD125 (Figure 4) could have been due to greater levels of toxin secretion, or to a different, more toxic type of $\beta$-exotoxin. Hence, culturing experiments in industrial fermenters that compare the timing of thermostable entomotoxin secretion among the tested strains are warranted to verify if their relative temporal patterns of $\beta$-exotoxin secretion (see below) are the same or not.

Due to an obvious practical facility and convenience, screening studies of large collections of microorganisms usually assess a number of isolates simultaneously, which frequently implies the use of the same culture time or same optical density (OD) for detection of their activity of interest. However, comparison of entomotoxic activities for different $B t$ strains obtained under these circumstances are intrinsically compromised by physiological variations observed among the isolates [28]. The concomitant collection of SNs in a same given time or OD can display toxin secretion with strain-specific variation, even when all had the same amount of cells at inoculation [28]. This may generate temporally distinct toxicity profiles for each strain, and consequently, potential misclassification of promising isolates (mainly if they are evaluated for toxicity in culturing times that are not the most favorable for identification of the toxic activities of interest). Interestingly, this same isolate-specific temporal effect was also observed in the secretion of thermostable $\beta$-exotoxins in our study (Figure 4). Therefore, such temporal and strain-specific variations in the production/secretion of toxins (of any nature) suggest that screening processes of $B t$ collections will only be effective to determine the most promising strains if sufficient knowledge of their physiology in different culture conditions over time is achieved. Taken together with the aspects discussed above, this information increases even further the technical capability to handle promising isolates for given toxins that also produce other undesired compounds. In the case of the strain Btt01, for instance, this information now makes it possible to constitute commercial preparations of endospores in a proper manner, by avoiding the culture moment in which the undesired toxin starts being secreted and/or by properly treating it before disposal.

Although $\beta$-exotoxin is highly toxic against insects, it also causes deleterious effects on non-target organisms, including mammals, because it is a nucleotide analog that affects RNA synthesis [11,12,50]. Because of this health and environmental threat, the World Health Organization has prohibited the use of $B t$ strains producing this toxin in bioinsecticide formulations [50], though some countries still use $\beta$-exotoxin products in specific control programs of flies that are resistant to other insecticides [51]. Considering the positive results of this study in relation to the potential use of this tropical strain in biocontrol strategies, based on its $\delta$-endotoxins composition $[25,26,44]$ and action in the field, it is here postulated that the assessment of $B t$ collections also for the presence of $\beta$-exotoxins appears to be a necessary routine in research labs and companies producing Bt-based bioinsecticides. One can, for 
example, include tests with SN-heated aliquots [28,31,32] to assess for entomotoxicity and thermostability; once the latter is detected, further inactivation-based characterization such as those employed here can be used. We argue that performing studies/verifications similar to these (including temporal assessments in culture) are not so difficult or expensive, and can provide a better understanding about the physiology of a given strain of interest, not only in relation to its toxins' arsenal, but also with regards to which culture conditions they are produced. The possibility of better decision-making processes about treatment or disposal of strains/toxins may allow more detailed analysis of benefits-costs ratios and can render more efficient strategies for production and marketing of biopesticides.

\section{Experimental Section}

\subsection{Bacillus Thuringiensis Strain and Culture Conditions}

A soil-derived B. thuringiensis var. tolworthi strain, labeled as "Btt01", originating from Foz do Iguaçu city (Paraná, Brazil), and belonging to the microbial bank of the National Maize and Sorghum Research Center (EMBRAPA-CNPMS), was used in this study. Two milliliters of $B t t 01$ from a $-80{ }^{\circ} \mathrm{C}$ stock were inoculated on $2 \mathrm{~L}$ of LB medium enriched with salts [31], and incubated under constant agitation of $200 \mathrm{rpm}$ and at $28^{\circ} \mathrm{C}$, until reaching a concentration of $\sim 10^{9}$ cells mL ${ }^{-1}$ by hemocytometer. This constituted a pre-inoculum culture for the subsequent large-scale fermentation. The total volume of this pre-inoculum $(2 \mathrm{~L})$ was added to a cylindrical industrial fermenter, containing $1500 \mathrm{~L}$ of the same medium. Culture was performed at $30^{\circ} \mathrm{C}$, pH 7.5 and $150 \mathrm{rpm}$, until reaching the concentration of $\sim 10^{9}$ endospores $\mathrm{mL}^{-1}$, which occurs between 22 and $24 \mathrm{~h}$ of culture. After fermentation, the endospores were separated from the supernatant by a filtration module Microdyn ${ }^{\circledR}$, with $0.2 \mathrm{~mm}$ polypropylene membrane under 20 psi for $8 \mathrm{~h}$, resulting in a concentration of $2-3 \times 10^{10}$ endospores $^{-1}$.

\subsection{Feeding Bioassays with Endospores of Btt01 against Spodoptera frugiperda}

A first feeding bioassay based on Cry toxins of Btt01 was performed on artificial diet [31], using a concentration of $10^{7}$ endospores $\mathrm{mL}^{-1}$, previously estimated as sufficiently efficient against fall armyworm [25]. Twenty-five artificial diets of $1 \mathrm{~cm}^{3}$ each were soaked for $1 \mathrm{~min}$ in $5 \mathrm{~mL}$ of the above suspension, let dry for $30 \mathrm{~min}$, and placed individually in $50 \mathrm{~mL}$ plastic containers. Two-day-old S. frugiperda larvae were added (one larva per diet cube, per container), and the containers were closed with transparent plastic lids [32]. The insects were kept at $25-28{ }^{\circ} \mathrm{C}$, in a photoperiod of $12 \mathrm{~h}: 12 \mathrm{~h}$ (light:dark), with the mortality assessed after 5 days of incubation. For the control treatment, diets were soaked in sterile distilled water.

A second bioassay was performed as described above, with corn leaves (from plants at the V4 stage) that were cut to $5 \mathrm{~cm}$ in length to replace the artificial diets. Tween $20^{\circledR}$ (Merck) was added to spore suspensions at $0.05 \%(v / v)$, to ensure that the toxins were homogeneously spread over the leaves. Three leaves and one larva were placed in each $50 \mathrm{~mL}$ plastic container covered with a transparent lid.

The third bioassay with the Cry proteins was carried out using entire corn plants at the V4 stage, which were obtained from corn seeds previously sowed in $\sim 200 \mathrm{~mL}$ of soil placed in $300 \mathrm{~mL}$ plastic containers (three plants per container). A volume of $7 \mathrm{~mL}$ of a $10^{7} \mathrm{Btt}$ endospores $\mathrm{mL}^{-1}$ suspension and 
$0.05 \%(v / v)$ Tween $20^{\circledR}$ were sprayed on the V4 plants, covering the entire surface of leaves, and let dry for $30 \mathrm{~min}$. Fifteen 2-days old $S$. frugiperda larvae were added to each container. Care was taken to avoid contact of leaves between different containers to prevent larvae escaping. To monitor for levels of such escaping, adhesive tapes were placed around the edge of the container, with the sticky side facing inwards; the escaping detected was negligible. The containers were kept at $25-28{ }^{\circ} \mathrm{C}$ with a photoperiod of $12 \mathrm{~h}: 12 \mathrm{~h}$ (light:dark), and the mortality was assessed after 5 days. For the control treatment, the plants were sprayed with sterile distilled water containing $0.05 \%(v / v)$ Tween $20^{\circledR}$. All treatments were replicated three times for each of the three bioassays.

\subsection{Entomotoxic Activity of Btt01 Endospores in the Field}

Tween $20^{\circledR}(0.05 \%)$ was added to a suspension of $\sim 10^{7}$ endospores $\mathrm{mL}^{-1}$ for application in the field. This suspension was applied by a $\mathrm{CO}_{2}$ backpack sprayer (spray bar with five flat-fan 110-03 nozzles), at a volume of $200 \mathrm{~L} \cdot \mathrm{ha}^{-1}$. The applications were made after 3:00 pm in two maize-planted areas. The first area corresponded to a non-irrigated cornfield with plants at the V7 stage. Climatic conditions during the field evaluation of this treatment were average $22{ }^{\circ} \mathrm{C}$ temperature, lack of rainfall, and a photoperiod of $\sim 13: 11 \mathrm{~h}$ (light:dark). At the moment of endospores application, this area showed natural infestation by $S$. frugiperda with $\sim 33 \%$ of plants displaying injury signs. The second area corresponded to irrigated maize by a center pivot, with an average of $20 \mathrm{~mm}$ water applied per week. The plants were also at the V7 stage, and the area showed $\sim 40 \%$ of plants displaying larvae injury signs. As negative control, only water with $0.05 \%(v / v)$ Tween $20^{\circledR}$ was sprayed on both areas. As positive control, $600 \mathrm{~mL} \cdot \mathrm{ha}^{-1}\left(=129 \mathrm{~g} \cdot \mathrm{ha}^{-1}\right)$ of methomyl insecticide (BR Lannate ${ }^{\circledR}$, DuPont) were applied, following the manufacturer's instructions. The plots were $4 \mathrm{~m}$ wide, $0.8 \mathrm{~m}$ spacing between rows of maize, and 25 and $50 \mathrm{~m}$ in length for non-irrigated and irrigated fields, respectively. The experimental design was randomized blocks with three treatments and three replicates. In addition, three applications were performed with a week's interval between them. The evaluation of the experiment was done one week after the third application, counting infestation in 15 plants of central lines in each block for non-irrigated, and in 25 plants for irrigated maize. The presence of live insects was verified by typical features, such as insect feces, scratched leaves, laid eggs, and the direct view of moving larvae or adults [52]. The counts of infested plants were transformed into infestation percentage, averaging the three replicates. These percentages were compared to those infestations obtained in the control. The efficiency was calculated using Abbott's formula, $\mathrm{E}(\%)=(\mathrm{C}-\mathrm{T}) / \mathrm{C} \times 100$, where $\mathrm{E}=$ percentage of efficiency; $\mathrm{C}=$ number of alive insects in the control; and $\mathrm{T}=$ number of alive insects in the treatment [53].

\subsection{Feeding Bioassays with Supernatant of Btt01 against S. frugiperda}

The supernatant $(\mathrm{SN})$ from $B t t 01$ culture in industrial fermenter, resulting from filtration system Microdyn (see above) and free of vegetative cells, endospores and crystals, was also tested for its toxicity against fall armyworm. In order to distinguish possible toxic activities between heat-sensitive and thermostable molecules, this SN was divided into two parts, with one part heated for 20 min in a water bath at $95{ }^{\circ} \mathrm{C}[10]$. In addition, the unheated SN was also diluted with sterile distilled water at 1:1, 1:20 and 1:100 proportions. The toxicity of all these treatments (three replicates per treatment) 
was assessed in bioassays against $S$. frugiperda on artificial diet, using the same general conditions for diets preparation, feeding and evaluation times described above.

Since highly thermostable toxic activities were detected in the above experiments, tests for inactivation of these activities were performed based on digestion of SN with alkaline phosphatase [33], and on temperature- and $\mathrm{pH}$-dependent hydrolysis of SN-containing phosphate-ester bonds [11]. These tests were carried out to determine whether such a toxic thermostable activity was due to the presence of $\beta$-exotoxins. Besides the Btt01, two other strains previously known to produce thermostable $\beta$-exotoxins, but from different genetic backgrounds, were used as positive controls: the HD125 (U.S. Department of Agriculture, Agricultural Research Services, Peoria, IL, USA) and T09 (Institute Pasteur, Paris, France) strains [34,35]. From pre-cultures set up as described above, cultures for the three strains were established in $50 \mathrm{~mL}$ LB broth in $250 \mathrm{~mL}$ flasks, with an initial concentration of $10^{6}$ cells $\mathrm{mL}^{-1}$. These cultures were incubated at $28^{\circ} \mathrm{C}$ under constant agitation of $200 \mathrm{rpm}$ for $96 \mathrm{~h}$. The SN was then separated from the biomass by centrifugation at $13,000 \times g$ for $10 \mathrm{~min}$. Half of the total $\mathrm{SN}$ volume was taken for toxin inactivation test by alkaline phosphatase: the $\mathrm{SN} \mathrm{pH}$ was raised to 9.0 by addition of $2 \mathrm{~N} \mathrm{NaOH}$ for better enzyme activity; alkaline phosphatase was added for $2 \mathrm{~h}$ in a $37{ }^{\circ} \mathrm{C}$ water bath, in four aliquots of $25 \mathrm{U}$ every $30 \mathrm{~min}$ [33]. The other half of SN volume was taken for toxin inactivation test by phosphate-ester hydrolysis mediated by $\mathrm{pH}$. In this case, the $\mathrm{SN} \mathrm{pH}$ was reduced to 1.5 by addition of $\mathrm{HCl}(37 \%)$, and then autoclaved for $20 \mathrm{~min}$ at $121{ }^{\circ} \mathrm{C}$ and $1 \mathrm{~atm}$ [11]. Following these steps of possible deactivation of thermostable activity (which would confirm the $\beta$-exotoxin nature of the SN insecticidal activity), these SN treatments (four replicates each) were applied to the same feeding bioassays against $S$. frugiperda on artificial diets.

Possible temporal variations in $\beta$-exotoxin detection among these three strains were verified by evaluating their SNs collected at different culture times. From $-80{ }^{\circ} \mathrm{C}$ stocks, these strains were set to grow in $50 \mathrm{~mL}$ flasks containing $10 \mathrm{~mL}$ of LB broth supplemented with salts [31], in the same overall conditions described for the pre-cultures (see above). After $12 \mathrm{~h}$ of growth, the number of cells was verified by hemocytometer. Volumes from these pre-cultures for each strain were adjusted to provide inocula at a same initial concentration of $10^{6}$ cells $\mathrm{mL}^{-1}$, in $50 \mathrm{~mL}$ cultures that were set and incubated as described above. For each strain, one $50 \mathrm{~mL}$ culture flask was set for each SN sampling at 48, 72, 96, 120 and $144 \mathrm{~h}$ of culture, respectively (total of five $50 \mathrm{~mL}$ flasks per strain). After each of these times, the corresponding culture was centrifuged at $13,000 \times g$ for $10 \mathrm{~min}$. The respective SNs were then carefully filtered through $3 \mathrm{MM}^{\circledR}$ filter paper and autoclaved $\left(121{ }^{\circ} \mathrm{C}\right.$ and $1 \mathrm{~atm}$ for $\left.20 \mathrm{~min}\right)$ prior to use in feeding bioassays against $S$. frugiperda (described above). Each isolate/time treatment was replicated 8 times. Time-collection treatments in which thermostable entomotoxic activity of SNs started to be detected indicate sufficient levels of $\beta$-exotoxin secretion.

\subsection{Statistical Analysis}

Considering the categorical type of variables and the counting nature of data for field (Figure 1), industrial fermentation supernatants (Figure 2) and $\beta$-exotoxins inactivation (Figure 3 ) experiments, chi-square analyses were employed on $2 \times 2$ contingency tables, comparing two treatments at a time (for Figure 2, the tests were performed only between individual \% SN and the water control). The goodness-of-fit tests for the hypothesis of no difference in dead/alive larvae between treatments 
considered a significance level of 5\%. The data from the temporal profiles of larvae mortality per isolates (Figure 4) were analyzed by generalized linear modeling with a binomial distribution and "logit" (logistic regression) link function to determine the difference between the proportions of live and dead insects in all performed "isolates" $\times$ "time-points" bioassays. Proportions were compared with a confidence level of $95 \%$ using the "glht" function of the "multcomp" library of the R statistical platform (R.2.15.1. version).

\section{Conclusions}

The results of this study, taken together, demonstrate that a single $B t$ strain can harbor and express different forms of toxins, which likely act in nature to help these bacteria live up to their characteristic as a bona fide pathogen of insect species [3,54]; this characteristic is advantageous in agricultural and biological control contexts if more than one useful type of toxin can be found for a single strain (e.g., Crys + Vips [28,32]). On the other hand, expression of multiple kinds of toxins, mainly when not all of them show beneficial features to non-target organisms (including humans), does require a deeper assessment of the genetics and physiology of each strain/isolate under investigation, as demonstrated by the case here reported. The key finding of this study is that a simultaneous analysis of pellet- and SN-related (thermolabile and thermostable) activities in $B t$ strains at different culturing times provides a more thorough and comprehensive understanding of their actual potential for biocontrol products manufacturing. This will certainly allow better-informed decision-making processes regarding economic viability of bioinsecticide production and employment of biological control strategies in any given agricultural system. We hope the approach here undertaken, as well as the ideas and considerations made, also become useful in other agricultural settings that deal with biological control programs, to fulfill the necessity of devising efficient strategies for food production with environmental sustainability.

\section{Acknowledgments}

We are grateful to the teams of Farroupilha Biocontrol Laboratory and National Maize and Sorghum Research Center (EMBRAPA-CNPMS) for great technical assistance in the experiments. We also thank Rachel Passos Rezende for the infrastructure provided. The work was supported by Brazilian Government funding agencies: PRONEX-FINEP in its first stages, and by National Council for Scientific and Technological Development (CNPq), FAPEMIG and Farroupilha Group afterwards. Doctoral fellowships were granted to Ronaldo Costa Argôlo Filho by CNPq (Process \# 564584/2008-8) and to Daniele Heloisa Pinheiro by Brazilian Federal Agency for Support and Evaluation of Graduate Education (CAPES).

\section{Author Contributions}

Ronaldo Costa Argôlo-Filho helped conceiving the study, participated in all tasks, did more than half of the experimental work, analyzed and interpret most experiments, drafted the manuscript and dealt with reviewers comments; Robson Luz Costa carried out the field experiments; Daniele Heloisa Pinheiro carried out the laboratory experiments concerning temporal analysis of SN activity of the three $B t$ strains; Fábio Mathias Corrêa performed the logistic regression analysis and provided the 
Figure 4B with explanations of its meaning and implications to the results; Fernando Hercos Valicente and Alan William Vilela Pomella participated in the design of the study, coordinated the execution of part of the experiments, were responsible for part of the funding and made critical assessments and interpretations; Leandro Lopes Loguercio conceived the general line of investigation, devised some experiments, participated in the results analyses and interpretations, was responsible for part of the funding, supervised RCAF in his Ph.D. studies and research, structured the manuscript, and dealt with reviewers comments. All authors read and approved the content of the manuscript.

\section{Conflicts of Interest}

The authors declare no conflict of interest.

\section{References}

1. Aronson, A.I.; Beckman, W.; Dunn, P. Bacillus thuringiensis and related insect pathogens. Microbiol. Rev. 1986, 50, 1-24.

2. Crickmore, N.; Zeigler, D.R.; Feitelson, J.; Schnepf, E.; van Rie, J.; Lereclus, D.; Baum, J.; Dean, D.H. Revision of the nomenclature for the Bacillus thuringiensis pesticidal crystal proteins. Microbiol. Mol. Biol. Rev. 1998, 62, 807-813.

3. Raymond, B.; Johnston, P.R.; Nielsen-LeRoux, C.; Lereclus, D.; Crickmore, N. Bacillus thuringiensis: An impotent pathogen? Trends Microbiol. 2010, 18, 189-194.

4. Schnepf, E.; Crickmore, N.; van Rie, J.; Lereclus, D.; Baum, J.; Feitelson, J.; Zeigler, D.R.; Dean, D.H. Bacillus thuringiensis and its pesticidal crystal proteins. Microbiol. Mol. Biol. Rev. 1998, 62, 775-806.

5. Zhao, J.Z.; Jun, C.; Collins, H.L.; Bates, S.L.; Roush, R.T.; Earle, E.D.; Shelton, A.M. Concurrent use of transgenic plants expressing a single and two Bacillus thuringiensis genes speeds insect adaptation to pyramided plants. Proc. Natl. Acad. Sci. USA 2005, 102, 8426-8430.

6. Kupke, T.; Lechner, M.; Kaim, G.; Gotz, F. Improved purification and biochemical properties of phosphatidylinositol-specific phospholipase C from Bacillus thuringiensis. Eur. J. Biochem. 1989, $185,151-155$.

7. Arora, N.; Ahmad, T.; Rajagopal, R.; Bhatnagar, R.K.A. Constitutively expressed 36 kDa exochitinase from Bacillus thuringiensis HD-1. Biochem. Biophys. Res. Commun. 2003, 307, $620-625$.

8. Donovan, W.P.; Engleman, J.T.; Donovan, J.C.; Baum, J.A.; Bunkers, G.J.; Chi, D.J.; Clinton, W.P.; English, L.; Heck, G.R.; Ilagan, O.M.; et al. Discovery and characterization of Sip1A: A novel secreted protein from Bacillus thuringiensis with activity against coleopteran larvae. Appl. Microbiol. Biotechnol. 2006, 72, 713-719.

9. Estruch, J.J.; Warren, G.W.; Mullins, M.A.; Nye, G.J.; Craig, J.A.; Koziel, M.G. Vip3A, a novel Bacillus thuringiensis vegetative insecticidal protein with a wide spectrum of activities against lepidopteran insects. Proc. Natl. Acad. Sci. USA 1996, 93, 5389-5394.

10. Farkas, J.; Sebesta, K.; Horkas, K.; Samek, Z.; Dolijs, J.; Storm, F. The structure of exotoxin of Bacillus thuringiensis var. gelechaiae. Collect. Czech. Chem. Commun. 1969, 34, 1118-1120. 
11. Levinson, B.L.; Kasyan, K.J.; Chiu, S.S.; Currier, T.C.; Gonzalez, J.M., Jr. Identification of $\beta$-exotoxin production, plasmids encoding $\beta$-exotoxin, and a new exotoxin in Bacillus thuringiensis by using high-performance liquid chromatography. J. Bacteriol. 1990, 172, 3172-3179.

12. Beebee, T.; Korner, A.; Bond, R.P. Differential inhibition of mammalian ribonucleic acid polymerases by an exotoxin from Bacillus thuringiensis: The direct observation of nucleoplasmic ribonucleic acid polymerase activity in intact nuclei. Biochem. J. 1972, 127, 619-634.

13. Demarchi, M. Análise da Conjuntura Agropecuária, Safra 2011/12: Milho; Secretary of Agriculture and Food Supply_Department of Rural Economy: Paraná, Brazil, 2011.

14. Cruz, I. A Lagarta-do-Cartucho na Cultura do Milho; 21 Technical Circular; Embrapa-CNPMS: Sete Lagoas-MG, Brazil, 1995.

15. Loguercio, L.L.; Carneiro, N.P.; Carneiro, A.A. Milho Bt: Alternativa biotecnológica para controle biológico de insetos-praga. Biotecnolog. Ciênc. Desenvolv. 2002, 24, 46-52.

16. Adamczyk, J.J., Jr.; Holloway, J.W.; Leonard, B.R.; Graves, J.B. Susceptibility of fall armyworm collected from different plant hosts to selected insecticides and transgenic Bt cotton. J. Cotton Sci. 1997, 1, 21-28.

17. Hardke, J.T.; Temple, J.H.; Leonard, R.B.; Jackson, R.E. Laboratory toxicity and field efficacy of selected insecticides against fall armyworm (Lepidoptera: Noctuidae). Fla. Entomol. 2011, 94, $272-278$.

18. Tholkappian, C.; Rajendran, S. Pesticide application and its adverse impact on health: Evidences from kerala. Int. J. Sci. Technol. 2011, 1, 56-59.

19. Sadek, M.M. Antifeedant and toxic activity of Adhatoda vasica leaf extract against Spodoptera littoralis (Lep., Noctuidae). J. Appl. Entomol. 2003, 127, 396-404.

20. Barreto, M.R.; Guimaraes, C.T.; Teixeira, F.F.; Paiva, E.; Valicente, F.H. Effect of Baculovirus spodoptera isolates in Spodoptera frugiperda (J.E. Smith) (Lepidoptera: Noctuidae) larvae and their characterization by RAPD. Neotrop. Entomol. 2005, 34, 67-75.

21. Delfín-González, H.; Bojórquez-Acevedo, M.; Manrique-Saide, P. Parasitoids of fall armyworm (Lepidoptera: Noctuidae) from a traditional maize crop in the mexican state of yucatan. Fla. Entomol. 2007, 90, 759-761.

22. Santos, W.L.; Freire, M.G.M.; Bogorni, P.C.; Vendramim, J.D.; Macedo, M.L.R. Effect of the Aqueous extracts of the seeds of Talisia esculenta and Sapindus saponaria on fall armyworm. Braz. Arch. Biol. Technol. 2008, 51, 373-383.

23. Arango, J.A.; Romero, M.; Orduz, S. Diversity of Bacillus thuringiensis strains from Colombia with insecticidal activity against Spodoptera frugiperda (Lepidoptera: Noctuidae). J. Appl. Microbiol. 2002, 92, 466-474.

24. Monnerat, R.; Martins, E.; Queiroz, P.; Ordúz, S.; Jaramillo, G.; Benintende, G.; Cozzi, J.; Real, M.D.; Martinez-Ramirez, A.; Rausell, C.; et al. Genetic variability of Spodoptera frugiperda Smith (Lepidoptera: Noctuidae) populations from Latin America is associated with variations in susceptibility to Bacillus thuringiensis Cry toxins. Appl. Environ. Microbiol. 2005, 77, 7029-7035.

25. Valicente, F.H.; Lana, U.G.P. Molecular characterization of the Bacillus thuringiensis (Berliner) strains 344 and 1644, efficient against fall armyworm Spodoptera frugiperda (J.E. Smith). Rev. Bras. Milho Sorgo 2008, 7, 195-209. 
26. Loguercio, L.L.; Santos, C.G.; Barreto, M.R.; Guimarães, C.T.; Paiva, E. Association of PCR and feeding bioassays as a large-scale method to screen tropical Bacillus thuringiensis isolates for a cry constitution with higher insecticidal effect against Spodoptera frugiperda (Lepidoptera: Noctuidae) larvae. Lett. Appl. Microbiol. 2001, 32, 362-367.

27. Valicente, F.H.; Barreto, M.R. Bacillus thuringiensis survey in Brazil: Geographical distribution and insecticidal activity against Spodoptera frugiperda (J.E. Smith) (Lepidoptera: Noctuidae). Neotrop. Entomol. 2003, 32, 639-644.

28. Argôlo-Filho, R.C.; Gomes, R.A., Jr.; Barreto, M.R.; Lana, U.G.P.; Valicente, F.H.; Loguercio, L.L. Growth variation among Bacillus thuringiensis strains can affect screening procedures for supernatant-secreted toxins against insect pests. Pest Manag. Sci. 2011, 67, 1184-1192.

29. Silva-Werneck, J.O.; De-Souza, M.T.; Dias, J.M.C.S.; Ribeiro, B.M. Characterization of Bacillus thuringiensis subsp. kurstaki strain S93 effective against the fall armyworm (Spodoptera frugiperda). Can. J. Microbiol. 1999, 45, 464-471.

30. He, J.; Luo, X.; Chen, S.; Cao, L.; Sun, M.; Yu, Z. Determination of spore concentration in Bacillus thuringiensis through the analysis of dipicolinate by capillary zone electrophoresis. J. Chromatogr. A 2003, 994, 207-212.

31. Barreto, M.R.; Loguercio, L.L.; Valicente, F.H.; Paiva, E. Insecticidal activity of culture supernatants from Bacillus thuringiensis Berliner strains against Spodoptera frugiperda Smith (Lepidoptera: Noctuidae) larvae. An. Soc. Entomol. Bras. 1999, 28, 675-685.

32. Loguercio, L.L.; Barreto, M.R.; Rocha, T.L.; Santos, C.G.; Teixeira, F.F.; Paiva, E. Combined analysis of supernatant-based feeding bioassays and PCR as a first-tier screening strategy for Vip-derived activities in Bacillus thuringiensis strains effective against tropical fall armyworm. J. Appl. Microbiol. 2002, 93, 269-277.

33. Bond, R.P.M.; Boyce, C.B.C.; French, S.J. A purification and some properties of an insecticidal exotoxin from Bacillus thuringiensis Berliner. Biochem. J. 1969, 114, 477-488.

34. Hernández, C.S.; Ferré, J.; Larget-Thiéry, I. Update on the detection of $\beta$-exotoxin in Bacillus thuringiensis strains by HPLC analysis. J. Appl. Microbiol. 2001, 90, 643-647.

35. Innes, T.C.M.; Bouwer, G. An improved bioassay for the detection of Bacillus thuringiensis $\beta$-exotoxin. J. Invertebr. Pathol. 2009, 101, 137-139.

36. Masson, L.; Erlandson, M.; Puzstai-Carey, M.; Brousseau, R.; Juárez-Pérez, V.; Frutos, R. A holistic approach for determining the entomopathogenic potential of Bacillus thuringiensis strains. Appl. Environ. Microbiol. 1998, 64, 4782-4788.

37. Rice, W.C. Specific primers for the detection of Vip3A insecticidal gene within a Bacillus thuringiensis collection. Lett. Appl. Microbiol. 1999, 28, 378-382.

38. Slininger, P.J.; Behle, R.W.; Jackson, M.A.; Schisler, D.A. Discovery and development of biological agents to control crop pests. Neotrop. Entomol. 2003, 32, 183-195.

39. Hoddle, M.S. The strength of biological control in the battle against invasive pests: A reply. Conserv. Biol. 2004, 18, 61-64.

40. Louda, S.M.; Stiling, P. The doubled-edged sword of biological control in conservation and restoration. Conserv. Biol. 2004, 18, 50-53.

41. Höfte, H.; Whiteley, H.R. Insecticidal crystal proteins of Bacillus thuringiensis. Microbiol. Rev. 1989, 53, 242-255. 
42. Bravo, A.; Sarabia, S.; Lopez, L.; Ontiveros, H.; Abarca, C.; Ortiz, A.; Ortiz, M.; Lina, L.; Villa-lobos, F.J.; Guadalupe, P.; et al. Characterization of cry genes in mexican Bacillus thuringiensis strain collection. Appl. Environ. Microbiol. 1998, 64, 4965-4972.

43. Luo, K.; Banks, D.; Adang, M.J. Toxicity, binding, and permeability analyses of four Bacillus thuringiensis Cry1 $\delta$-endotoxins using brush border membrane vesicles of Spodoptera exigua and Spodoptera frugiperda. Appl. Environ. Microbiol. 1999, 65, 457-464.

44. Valicente, F.H.; Barreto, M.R.; Vasconcelos, M.J.V.; Figueiredo, J.E.F.; Paive, E. PCR identification of Cry I genes in Bacillus thuringiensis strains that are efficient against fall armyworm Spodoptera frugiperda (J.E. Smith) (Lepidoptera: Noctuidae). An. Soc. Entomol. Bras. 2000, 29, 147-153.

45. Cornell Guide for Integrated Field Crop Management 2012. Available online: http://www. ipmguidelines.org/FieldCrops/ (accessed on 10 October 2012).

46. Keller, M.; Sneh, B.; Strizhov, N.; Prudovsky, E.; Regev, A.; Koncz, C.; Schell, J.; Zilberstein, A. Digestion of delta-endotoxin by gut proteases may explain reduced sensitivity of advanced instar larvae of Spodoptera littoralis to Cry1C. Insect Biochem. Mol. Biol. 1996, 26, 365-373.

47. Kostichka, K.; Warren, G.W.; Mullins, M.; Mullins, A.D.; Palekar, N.V.; Craig, J.A.; Koziel, M.G.; Estruch, J.J. Cloning of a $c r y V$-type insecticidal protein gene from Bacillus thuringiensis: The cryV-encoded protein is expressed early in stationary phase. J. Bacteriol. 1996, 178, 2141-2144.

48. Tabashnik, B.E. Evolution of resistance to Bacillus thuringiensis. Annu. Rev. Entomol. 1994, 39, 47-79.

49. Espinasse, S.; Gohar, M.; Chaufaux, J.; Buisson, C.; Perchat, S.; Sanchis, V. Correspondence of high levels of beta-exotoxin I and the Presence of crylB in Bacillus thuringiensis. Appl. Environ. Microbiol. 2002, 68, 4182-4186.

50. WHO_World Health Organization. Microbial Pest Control Agent: Bacillus thuringiensis; World Health Organization: Geneva, Switzerland, 1999.

51. Carlberg, G.; Kihamia, C.M.; Minjas, J. Microbial control of flies in latrines in Dares Salaam with a Bacillus thuringiensis (serotype 1) preparation, Muscabac. World J. Appl. Microbiol. Biotechnol. 1985, $1,33-44$.

52. Capalbo, D.M.F.; Valicente, F.H.; Moraes, I.O.; Pelizer, L.H. Solid-state fermentation of Bacillus thuringiensis tolworthi to control fall armyworm in maize. Electron. J. Biotechnol. 2001, 4, 112-115.

53. Nakano, O.; Silveira-Neto, S.; Zucchi, R.A. Entomologia Econômica; Luiz de Queiroz College of Agriculture (ESALQ-USP): Piracicaba, Brazil, 1981.

54. Argôlo-Filho, R.C.; Loguercio, L.L. Bacillus thuringiensis is an environmental pathogen and host-specificity has developed as an adaptation to human-generated ecological niches. Insects 2014, 5, 62-91.

(C) 2014 by the authors; licensee MDPI, Basel, Switzerland. This article is an open access article distributed under the terms and conditions of the Creative Commons Attribution license (http://creativecommons.org/licenses/by/3.0/). 